\title{
THE ASSOCIATIONS OF WORK STYLE AND PHYSICAL EXERCISE WITH THE RISK OF WORK-RELATED MUSCULOSKELETAL DISORDERS IN NURSES
}

\section{YONGCHENG YAO ${ }^{1,2}$, SHAN ZHAO ${ }^{1}$, ZHEN AN $^{1}$, SHOUYING WANG ${ }^{1}$, HONGBIN LI ${ }^{1}$, LINGENG LU ${ }^{3}$, and SANQIAO YAO ${ }^{1}$}

${ }^{1}$ Xinxiang Medical University, Xinxiang, China

School of Public Health

${ }^{2}$ Zhengzhou University, Zhengzhou, China

School of Basic Medical Sciences

${ }^{3}$ Yale University, New Haven, USA

Yale School of Public Health, School of Medicine, Department of Chronic Disease Epidemiology, Yale Cancer Center

\begin{abstract}
Objectives: This study aimed to investigate the prevalence of work-related musculoskeletal disorders (WMSD) in nurses, and to explore the association of work style and physical exercise with WMSD in this professional group. Material and Methods: In this study, a cross-sectional survey design was applied. A questionnaire survey was conducted on 692 nurses in 5 municipal hospitals, in the period August-October 2015. The survey included personal information, lifestyle, physical exercise and symptoms of WMSD. Chi ${ }^{2}$ test and logistic regression were used to identify the risk factors of WMSD. Results: The prevalence of WMSD was $84 \%$ in all parts of the body in the previous year, with the highest prevalence in the neck (68.2\%), followed by waist $(67.6 \%)$ and shoulder (54.6\%). Both univariate and multivariate analyses showed that physical exercise, night shifts and staying up late were associated with WMSD in nurses. The lack of exercise, night shifts and a tendency to stay up significantly increased the risk of WMSD $(\mathrm{p}<0.05)$. Conclusions: The prevalence of musculoskeletal disorders among the municipal hospital nursing staff is high. An elevated risk of WMSD is observed in nurses who do not do exercises, work shifts and stay up late. Int J Occup Med Environ Health. 2019;32(1):15-24
\end{abstract}

Key words:

risk factors, nurses, physical exercise, work-related musculoskeletal disorders, work style, staying up

\section{INTRODUCTION}

A work-related musculoskeletal disorder (WMSD) is an injury of the muscles, tendons, ligaments, nerves, joints, cartilage, bones or blood vessels in the arms, legs, head, neck or back, which is caused or aggravated by work tasks such as lifting, pushing and pulling. Its symptoms include pain, stiffness, swelling, numbness and tingling [1]. David's 5-year study of 12426 participants representing 47 different occupations in 18 countries showed that occupational groups (such as civilian workers, food processors, nurses,

Funding: this work was supported under a support project for the disciplinary group of psychology and neuroscience, Xinxiang Medical University; scientific and technological projects of the Science and Technology Department of Henan Province (project No. 001702005 entitled "Henan Provincial Postdoctoral Research," project manager: Yongcheng Yao).

Received: February 9, 2018. Accepted: April 19, 2018.

Corresponding author: Sanqiao Yao, Xinxiang Medical University, School of Public Health, Xinxiang, Henan 453003, China (e-mail: 1153483589@qq.com). 
operators, etc.) had a higher prevalence of WMSD, especially nurses [2]. The research in various countries and regions also showed that nursing staff had a high prevalence of WMSD, e.g., 70\% in Estonia [3] and 85\% in the Kingdom of Saudi Arabia [4].

A work-related musculoskeletal disorder not only brings great harm to people's health, but also causes serious absenteeism and economic losses. In addition, more than 3 million days of absence from work in 2010 could be attributed to lower limb pain in the European Union [5]. Official data from the U.S. suggest that WMSD represents $40 \%$ of the amount of compensation for work-related illnesses, with annual costs higher than USD 50 billion [6], and 19360 days of absence from work ranked U.S. nurses second in all industries in 2015 [7].

Factors that are mainly related to WMSD in nursing staff include handling, lifting a patient, prolonged bad posture, etc. [8-10]. Nurses frequently have bad posture, including standing for a long time, remaining bent over, or bowing. Specific performance is required, such as bending for intramuscular or intravenous injections, making beds, helping patients go to and get out of their bed, turning over, or knocking back expectoration, and performing other basic procedures In addition, nurses usually have a 3-shift work system, and those on night shifts have to stay up all night. This day and night shift work system greatly affects the health of nurses and their working conditions, contributing to the frequent occurrence of WMSD. Moreover, due to heavy workloads and family responsibilities, less time is left for nurses to do physical exercise. Previous studies have shown that age, gender, psychosocial factors, workload and the mode of operation are important risk factors in musculoskeletal disorders [11-13]. However, how physical exercise and work style affect WMSD in nurses is yet to be characterized. Therefore, the purpose of this study was to investigate the relationship between physical exercise, work style and musculoskeletal disorders in nurses.

\section{MATERIAL AND METHODS}

\section{Study population}

Convenience sampling of registered nurses from 5 municipal hospitals of Zhengzhou, Henan Province, China, was conducted in the period from August till October 2015. All the respondents were informed on the survey and their formal consent was obtained. The inclusion criteria included: age $\geq 18$ years, the licensed practical nurses with work experience of $>12$ months in a permanent position, and no obvious physical and mental illness. Of the 800 distributed questionnaires, 692 (86.5\%) were collected and considered valid.

\section{Data collection}

A nominated survey coordinator at each hospital distributed the revised questionnaires, based on both the Nordic and the Dutch questionnaires, among nurses in AugustOctober 2015.

\section{Study instruments}

Socio-demographic characteristics

The information in the questionnaire included:

- demographics, including gender and age,

- work-related factors, such as working department, physical exercise, work style, shift (day or night) work, and the frequency of night shifts.

\section{Work-related musculoskeletal disorders}

The following regions of the body were included in the survey: back, shoulder, neck, elbow, lower back, hand/wrist, hip, knee, and ankle/foot. The symptoms included in the questionnaire were as follows: tendon inflammations and related conditions (tenosynovitis, epicondylitis, bursitis), nerve compression disorders (carpal tunnel syndrome, sciatica) and osteoarthrosis, as well as less standardized conditions such as myalgia, low back pain and other regional pain syndromes, not attributable to any known pathology [14]. Symptom presence was defined as having experienced work-related discomfort, numbness, pain or restricted 
movement in any part of the body, and its duration for more than a day, along with failure to recover after rest. This was determined with yes/no responses to the Chinese version of the musculoskeletal questionnaire which was used to identify the symptoms occurring in the previous 12 months [15].

\section{Data analysis}

Data were recorded and analyzed using EpiData3.1 and SAS (9.4) software. The qualitative data were descriptively analyzed by calculating percentage rates or frequencies, and the quantitative data were presented as mean \pm standard deviation $(\mathrm{M} \pm \mathrm{SD})$. $\mathrm{Chi}^{2}$ test and unconditional logistic regression analyses were used to analyze the association between the risk factors and WMSD. A p value $<0.05$ was considered statistically significant.

\section{RESULTS}

The characteristics of the surveyed nurses are shown in Table 1 . Out of 692 participants, 37 were men and 655 women. The average age of the participants was 28.9 (SD $=5.6$ with the range of 18-53. The average length of their work experience was 7.6 years ( $\mathrm{SD}=6.2$ years), with the range of $1-33$ years.

\section{The prevalence of WMSD}

The prevalence of WMSD in working year 1 and in the previous 12 months was $89.6 \%$ and $84 \%$, respectively. The most commonly affected regions were the neck, waist and shoulder, with the annual prevalence of $68.2 \%, 67.6 \%$ and $54.6 \%$, respectively. The lowest prevalence was recorded for the elbow (17.3\%) (Figure 1). In view of the prevalence rates, the authors decided to focus on the top 3 body regions with the high prevalence of WMSD in the analysis of risk factors.

\section{The association between individual risk factors and WMSD in the neck, waist and shoulder}

To investigate the association between individual risk factors and WMSD, the authors first performed univariate analyses,
Table 1. Characteristics of the participants in the questionnaire survey conducted among nurses in 5 municipal hospitals in China, in August-October 2015

\begin{tabular}{lcc}
\hline \multirow{2}{*}{ Variable } & \multicolumn{2}{c}{$\begin{array}{c}\text { Respondents } \\
\text { (N=692) }\end{array}$} \\
\cline { 2 - 3 } & $\mathrm{n}$ & $\%$ \\
\hline Age & 142 & 20.5 \\
$18-24$ & 288 & 41.6 \\
$25-29$ & 171 & 24.7 \\
$30-34$ & 91 & 13.2 \\
$\geq 35$ & & \\
Gender & 37 & 5.3 \\
male & 655 & 94.7 \\
female & & \\
Length of service & 327 & 47.3 \\
1-5 years & 191 & 27.6 \\
6-10 years & 174 & 25.1 \\
$\geq 11$ years & & \\
Department & 69 & 10.0 \\
emergency & 157 & 22.7 \\
surgical & 35 & 5.1 \\
pediatric & 86 & 12.4 \\
obstetrics and gynecology & 184 & 26.6 \\
internal medicine & 161 & 23.3 \\
other & & \\
\hline
\end{tabular}

the results of which are shown in Table 2. Physical exercise, night shifts and staying up were significantly associated with both neck and waist pain $(\mathrm{p}<0.05)$. The working department, night shifts and staying up were associated with shoulder pain $(\mathrm{p}<0.05)$. The prevalence of WMSD of the neck in nurses who exercised 1-2 times/week (30-60 min/time) was lower. The prevalence of WMSD of the waist in nurses who exercised 3-4 times/week was also lower. The prevalence of WMSD in nurses with irregular work styles was the highest, rising with regular shift work and staying up. The prevalence of WMSD of the shoulder in nurses employed in pediatric departments was the highest (Table 2).

Table 3 shows the multivariate analysis results, in which such factors as the working department, physical exercise, night shifts and staying up were included in an un- 


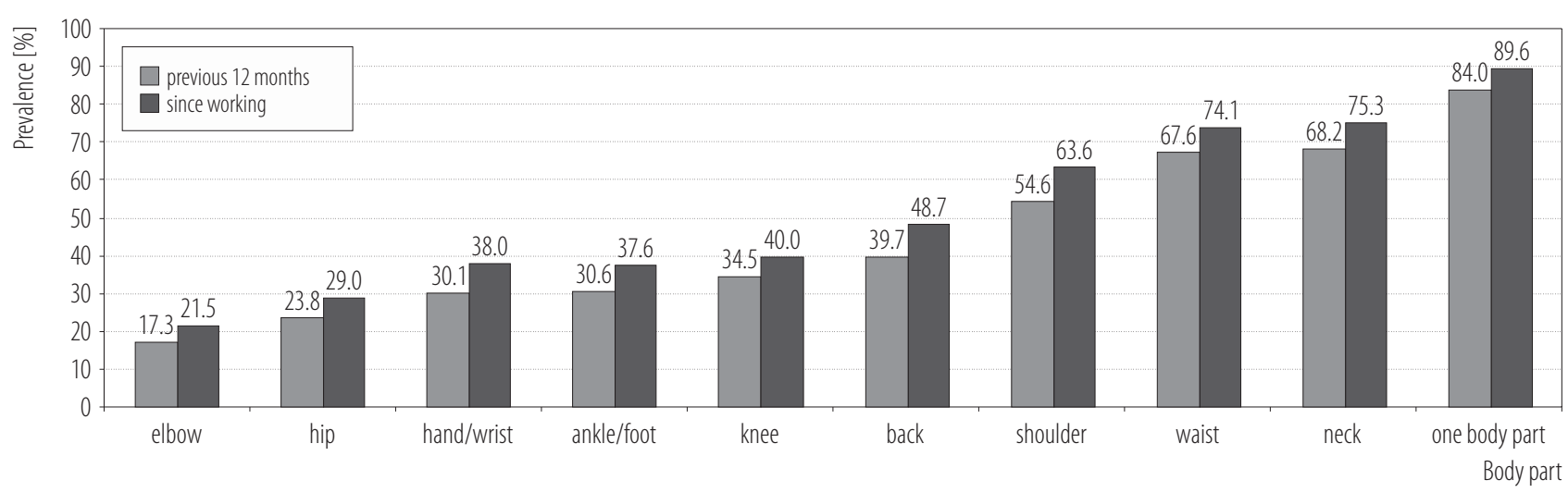

Figure 1. The prevalence of work-related musculoskeletal disorders (WMSDs) in various parts of the body, based on the questionnaires survey conducted among nurses in 5 municipal hospitals in China, in August-October 2015

conditional logistical model. The results showed that the surgical and internal medicine departments, the lack of exercise, always working night shifts and staying up significantly increased the risk of WMSD.

Neck pain had statistically significant associations with the following responses: surgical department $(\mathrm{OR}=2.14$, 95\% CI: 1.08-4.24), internal medicine department (OR = 2.34, 95\% CI: $1.29-4.27)$, seldom exercise $(\mathrm{OR}=2.53$, 95\% CI: 1.41-4.54), seldom staying up (OR $=4.14$, 95\% CI: 1.57-10.97), and sometimes staying up ( $\mathrm{OR}=2.84$, 95\% CI: 1.18-6.82), respectively.

Waist pain had statistically significant associations with the following responses: surgical department $(\mathrm{OR}=2.32$, 95\% CI: $1.20-4.48)$, exercise 1-2 times/week (OR $=2.84$, 95\% CI: 1.44-5.60), seldom exercise ( $\mathrm{OR}=1.96,95 \%$ CI: 1.08-3.54), never exercise (OR $=1.60,95 \%$ CI: 1.10-2.35), seldom staying up (OR $=3.67,95 \% \mathrm{CI}: 1.41-9.56)$, and sometimes staying up (OR $=2.45,95 \% \mathrm{CI}: 1.04-5.81)$, respectively. Shoulder pain had statistical significant associations with the following responses: obstetrics and gynecology department $(\mathrm{OR}=0.40,95 \%$ CI: 0.17-0.94), internal medicine department (OR $=1.99,95 \%$ CI: $1.13-3.51)$, seldom exercise $(\mathrm{OR}=2.07,95 \% \mathrm{CI}: 1.17-3.68)$, never exercise (OR = 1.44, $95 \% \mathrm{CI}: 1.01-2.05)$, always night shift $(\mathrm{OR}=1.76$, $95 \%$ CI: $1.01-3.06)$, and seldom staying up ( $\mathrm{OR}=2.55$, 95\% CI: 1.01-6.45), respectively.

\section{DISCUSSION}

Nurses are susceptible to cumulative work-related musculoskeletal disorders. This study showed that the general prevalence o WMSD among nurses in the previous 12 months was $82.1 \%$, which was similar to the prevalence of $82.38 \%$ reported by Tang et al. [16], whereas it was lower than that of 91.4\% reported in a previous study [17], and higher than that of $70 \%$ reported for Estonia [3]. The differences in the prevalence of WMSD between various countries and regions may be due to different the commencement of work conditions. In China, the population is much larger compared to other countries. The increasing health requirements, particularly with the development of the economy, and the relative shortage of nursing staff lead to heavier workloads for nurses. The Ministry of Health recommends a general nurse-patient ratio of 1:8 [18], which is much higher than the ratios of 1:5 in California and 1:4 in Australia [19,20]. However, the authors could not rule out the possibility that the difference in the incidence of WMSD was due to the lack of uniform diagnostic criteria and clinical examinations about WMSD [21].

The circadian clock plays an important role for human health [22]. Its disruption is associated with lots of adverse health effects [23]. The night-shift system of hospital work leads to interrupting the nurses' circadian clock, thereby affecting their sleep, diet, family life, social activities and so on, and altering the endocrine system. These changes 


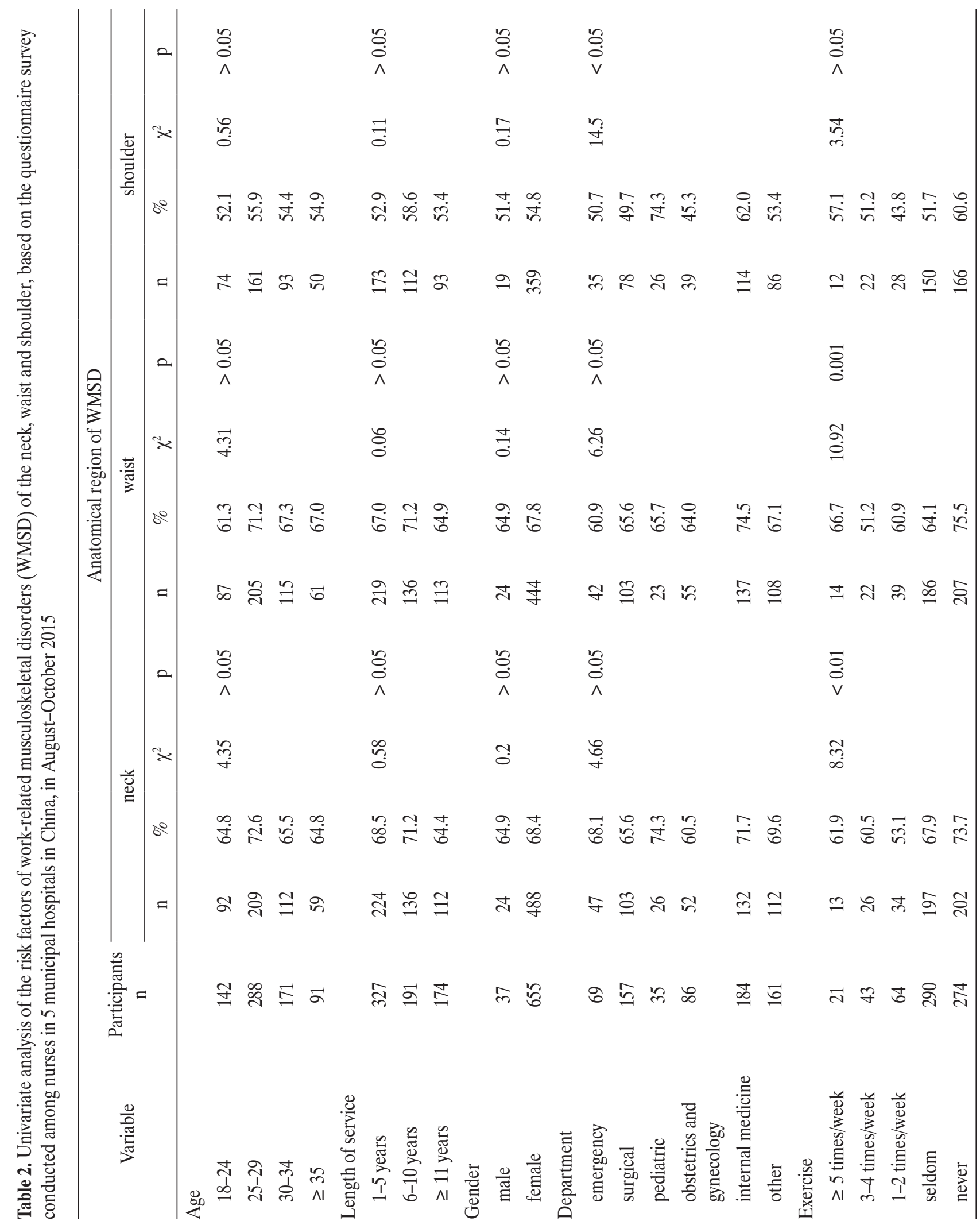




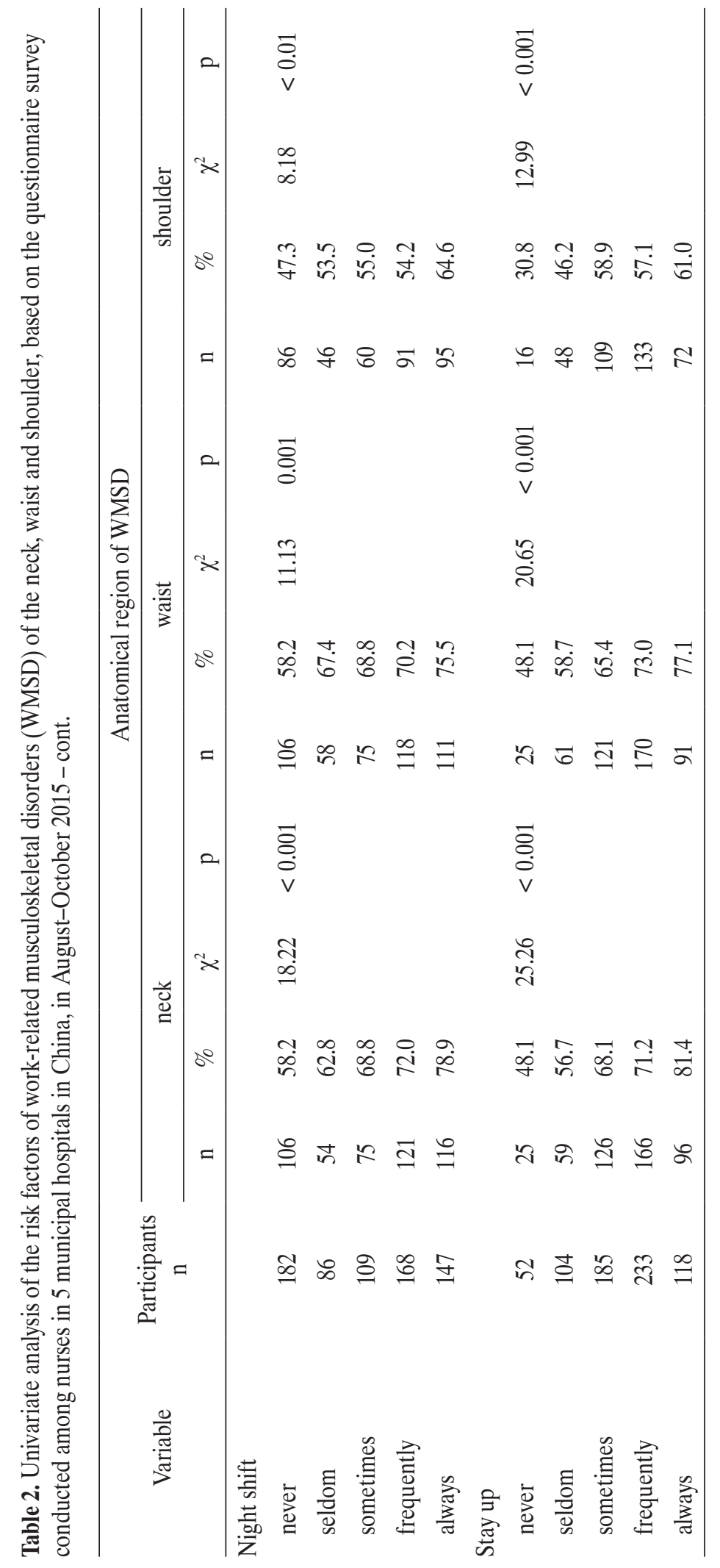


Table 3. Logistic regression analysis of the risk factors of work-related musculoskeletal disorders (WMSD) of the neck, waist and shoulder, based on the questionnaire survey conducted among nurses in 5 municipal hospitals in China, in August-October 2015

\begin{tabular}{|c|c|c|c|c|c|c|}
\hline \multirow{3}{*}{ Variable } & \multicolumn{6}{|c|}{ Anatomical region of WMSD } \\
\hline & \multicolumn{2}{|r|}{ neck } & \multicolumn{2}{|c|}{ waist } & \multicolumn{2}{|c|}{ shoulder } \\
\hline & OR & $95 \% \mathrm{CI}$ & OR & $95 \% \mathrm{CI}$ & OR & $95 \% \mathrm{CI}$ \\
\hline \multicolumn{7}{|l|}{ Department } \\
\hline emergency & 1.00 & & 1.00 & & 1.00 & \\
\hline surgical & 2.14 & $1.08-4.24^{*}$ & 2.32 & $1.20-4.48^{*}$ & 1.69 & $0.90-3.16$ \\
\hline pediatric & 1.58 & $0.95-2.61$ & 1.41 & $0.86-2.32$ & 1.46 & $0.92-2.33$ \\
\hline obstetrics and gynecology & 0.83 & $0.35-1.97$ & 1.11 & $0.49-2.50$ & 0.40 & $0.17-0.94 *$ \\
\hline internal medicine & 2.34 & $1.29-4.27^{* *}$ & 1.73 & $0.95-3.13$ & 1.99 & $1.13-3.51^{*}$ \\
\hline other & 1.54 & $0.92-2.59$ & 1.11 & $0.66-1.85$ & 1.01 & $0.63-1.62$ \\
\hline \multicolumn{7}{|l|}{ Exercise } \\
\hline$\geq 5$ times/week & 1.00 & & 1.00 & & 1.00 & \\
\hline 3-4 times/week & 1.28 & $0.50-3.33$ & 1.16 & $0.44-3.09$ & 0.94 & $0.37-2.39$ \\
\hline 1-2 times/week & 1.75 & $0.87-3.49$ & 2.84 & $1.44-5.60 * *$ & 1.54 & $0.78-3.02$ \\
\hline seldom & 2.53 & $1.41-4.54^{* *}$ & 1.96 & $1.08-3.54^{*}$ & 2.07 & $1.17-3.68^{*}$ \\
\hline never & 1.25 & $0.86-1.84$ & 1.60 & $1.10-2.35^{*}$ & 1.44 & $1.01-2.05^{*}$ \\
\hline \multicolumn{7}{|l|}{ Night shift } \\
\hline never & 1.00 & & 1.00 & & 1.00 & \\
\hline seldom & 1.68 & $0.79-3.54$ & 1.26 & $0.60-2.65$ & 1.86 & $0.93-3.71$ \\
\hline sometimes & 1.23 & $0.55-2.77$ & 0.80 & $0.35-1.82$ & 1.49 & $0.70-3.18$ \\
\hline frequently & 1.32 & $0.62-2.81$ & 1.01 & $0.47-2.14$ & 1.94 & $0.97-3.86$ \\
\hline always & 1.14 & $0.62-2.13$ & 1.14 & $0.62-2.09$ & 1.76 & $1.01-3.06^{*}$ \\
\hline \multicolumn{7}{|l|}{ Stay up } \\
\hline never & 1.00 & & 1.00 & & 1.00 & \\
\hline seldom & 4.14 & $1.57-10.97^{* *}$ & 3.67 & $1.41-9.56^{* *}$ & 2.55 & $1.01-6.45^{*}$ \\
\hline sometimes & 2.84 & $1.18-6.82 *$ & 2.45 & $1.04-5.81^{*}$ & 1.27 & $0.57-2.81$ \\
\hline frequently & 1.70 & $0.78-3.72$ & 1.80 & $0.84-3.85$ & 0.67 & $0.34-1.35$ \\
\hline always & 1.56 & $0.81-3.02$ & 1.14 & $0.61-2.16$ & 0.77 & $0.43-1.36$ \\
\hline
\end{tabular}

${ }^{* *} \mathrm{p}<0.01,{ }^{*} \mathrm{p}<0.05$

have been shown in association with WMSD in nursing staff $[24,25]$. At the same time, the lack of sleep during night shifts leads to an increased incidence of WMSD [26]. Staying up causes a variety of damages to the body, entailing a series of symptoms such as fatigue, lack of energy and an impaired immune system. Further symptoms of involuntary neurosis, such as cold, gastrointestinal infections and allergies, are also likely to occur. Staying up late for prolonged periods induces insomnia, forgetfulness, irritability, anxiety, and other nervous and mental symptoms. This study shows that the prevalence of WMSD in nurses with irregular working styles, regular night-shifts or a tendency to stay up was the highest. Compared to nurses who neither worked at night nor stayed up, the risk of WMSD for those who stayed up and worked night shifts was significantly higher. 
Physical exercise can improve the body's sensitivity and coordination of muscles, and the response speed and effective action of human brain. It can also effectively delay the age-related decline in muscle strength. Proper physical exercise can effectively reduce the prevalence of low back pain (LBP) in handling workers and acts as a protective factor for LBP [27]. This study shows that the prevalence of WMSD is lower in nurses who regularly do physical exercise than in those who lack exercise.

The nurse-patient and doctor-nurse ratios in various departments may result in differences in their workloads. This discrepancy may explain the difference in the prevalence of musculoskeletal disorders in nurses employed in different departments. The results of this study show that the prevalence of WMSD of the shoulder in pediatric nurses was the highest. Since the number of pediatric nurses is usually much lower while pediatric patients are difficult to communicate with and manage, pediatric nurses spend more time and efforts, and hence the increased risk of WMSD.

This study did not find a correlation between WMSD and age, and only the prevalence of WMSD of the waist in the nursing staff with work experience of 6-15 years was the highest. This is consistent with the findings by Cheng [17], but not with the results of other studies [28,29]. This inconsistency might have resulted from different age structures of nurses employed in these studies.

\section{Study limitations}

The measurement and symptoms of WMSD were selfreported and might therefore, exhibit self-report bias. The participants may have underestimated or overestimated their levels of WMSD.

\section{CONCLUSIONS}

This study shows a high prevalence of WMSD in nurses, with the highest prevalence of neck pain, followed by waist and shoulder pain, whereas the prevalence of cervical pain is the lowest. The authors also found that the lack of exercise, regular night shifts and staying up significantly increased the risk of WMSD. Relevant policies and measures are urgently needed to reduce the impact of WMSD on nurses, for example, reducing the frequency of night shifts, enhancing the program of regular exercises or relaxation practice during breaks, and educating nurses on how to do exercise in a limited area and at short intervals. Future studies should focus on how to reduce the need to stay up and improve exercise programs to effectively reduce the prevalence of musculoskeletal disorders in nurses.

\section{ACKNOWLEDGMENTS}

The authors thank all the nurses from the hospitals of Zhengzhou in Henan, China, who participated in this study. The authors are grateful to Ms. Samantha Williams for her critical reading of this manuscript.

\section{REFERENCES}

1. The National Institute for Occupational Safety and Health (NIOSH). How to prevent musculoskeletal disorders [Internet]. Department of Health and Human Services; Centers for Disease Control and Prevention; National Institute for Occupational Safety and Health; 2012 [cited 2018 Jan 20]. Available from: http://www.cdc.gov/niosh/docs/2012-120/pdfs/ 2012-120.pdf.

2. Coggon D, Ntani G, Palmer KT, Felli VE, Harari R, Barrero LH, et al. Disabling musculoskeletal pain in working populations: Is it the job, the person, or the culture? Pain. 2013;154(6):856-63, https://doi.org/10.1016/j.pain.2013. 02.008 .

3. Freimann T, Paasuke M, Merisalu E. Work-related psychosocial factors and mental health problems associated with musculoskeletal pain in nurses: A cross-sectional study. Pain Res Manag. 2016;2016:9361016, https://doi.org/ 10.1155/2016/9361016.

4. Attar SM. Frequency and risk factors of musculoskeletal pain in nurses at a tertiary centre in Jeddah, Saudi Arabia: 
A cross sectional study. BMC Res Notes. 2014;7:61, https:// doi.org/10.1186/1756-0500-7-61.

5. Garcia MG, Graf M, Laubli T. Lower limb pain among workers: A cross-sectional analysis of the fifth European Working Conditions Survey. Int Arch Occup Environ Health. 2017;90(7):575-85, https://doi.org/10.1007/s00420-017-1220-4.

6. Da CJT, Baptista JS, Vaz M. Incidence and prevalence of upper-limb work related musculoskeletal disorders: A systematic review. Work. 2015;51(4):635-44, https://doi.org/ 10.3233/WOR-152032.

7. Bureau of Labor Statistics [Internet]. Washington: The Bureau; 2015 [cited 2018 Jan 20]. Nonfatal occupational injuries and illnesses requiring days away from work; 2015. Available from: https://www.bls.gov/news.release/osh2.nr0.htm.

8. Powell-Cope G, Toyinbo P, Patel N, Rugs D, Elnitsky C, Hahm B, et al. Effects of a national safe patient handling program on nursing injury incidence rates. J Nurs Adm. 2014;44(10):525-34, https://doi.org/10.1097/NNA.00000000 00000111.

9. Pompeii LA, Lipscomb HJ, Dement JM. Surveillance of musculoskeletal injuries and disorders in a diverse cohort of workers at a tertiary care medical center. Am J Ind Med. 2008;51(5):344-56, https://doi.org/10.1002/ajim.20572.

10. Wenjuan MO, Zhang P. [Investigation on occupational factors affecting musculoskeletal injury of nurses]. J Nurs Sci. 2009;24(19):54-7, https://doi.org/10.3870/hlxzz.2009.19.054. Chinese.

11. Marras WS. The complex spine: The multidimensional system of causal pathways for low-back disorders. Hum Factors. 2012;54(6):881-9, https://doi.org/10.1177/001872081245 2129.

12. Munabi IG, Buwembo W, Kitara DL, Ochieng J, Mwaka ES. Musculoskeletal disorder risk factors among nursing professionals in low resource settings: A cross-sectional study in Uganda. BMC Nurs. 2014;13(1):7, https://doi.org/ 10.1186/1472-6955-13-7.

13. Reme SE, Dennerlein JT, Hashimoto D, Sorensen G. Musculoskeletal pain and psychological distress in hospital patient care workers. J Occup Rehabil. 2012;22(4):503-10, https://doi.org/10.1007/s10926-012-9361-5.

14. Punnett L, Wegman DH. Work-related musculoskeletal disorders: The epidemiologic evidence and the debate. J Electromyogr Kinesiol. 2004;14(1):13-23, https://doi.org/ 10.1016/j.jelekin.2003.09.015.

15. Du WW, Wang S, Wang JX, He LH, Wu SS, Li JY, et al. [The assessment of reliability and validity of musculoskeletal questionnaire]. Zhonghua Lao Dong Wei Sheng Zhi Ye Bing Za Zhi. 2012;30(5):335-8, https://doi.org/10.3760/cma. j.issn.1001-9391.2012.05.004. Chinese.

16. Qilan T, Xiaoping L, Aixia W. [Relationship between nurse's occupational musculoskeletal injury and presenteeism]. Chin J Pract Nurs. 2014;30(17):35-8, https://doi.org/10.3760/ cma.j.issn.1672-7088.2014.17.010. Chinese.

17. Cheng CC, Wang JP, Ling-Ling WU, Shen Y, Jin KZ. [Prevalence of musculoskeletal disorders and associated risk factors of healthcare workers in a hospital of Shanghai].J Environ Occup Med. 2017;34(1):15-21, https://doi.org/10.13213/j.cnki. jeom.2017.16602. Chinese.

18. Jiang H, Li H, Ma L, Gu Y. Nurses' roles in direct nursing care delivery in China. Appl Nurs Res. 2015;28(2):132-6, https://doi.org/10.1016/j.apnr.2014.09.003.

19. Chapman SA, Spetz J, Seago JA, Kaiser J, Dower C, Herrera $\mathrm{C}$. How have mandated nurse staffing ratios affected hospitals? Perspectives from California hospital leaders. J Healthc Manag. 2009;54(5):321-33, https://doi.org/ 10.1097/00115514-200909000-00007.

20. Gerdtz MF, Nelson S. 5-20: A model of minimum nurse-topatient ratios in Victoria, Australia. J Nurs Manag. 2007;15(1): 64-71, https://doi.org/10.1111/j.1365-2934.2006.00657.x.

21. Punnett L. Musculoskeletal disorders and occupational exposures: How should authors judge the evidence concerning the causal association? Scand J Public Health. 2014;42(13 Suppl):49-58, https://doi.org/10.1177/1403494813517324.

22. Zisapel N. New perspectives on the role of melatonin in human sleep, circadian rhythms and their regulation. Br J Pharmacol. 2018 175;42(13):3190-9, https://doi.org/10.1111/bph.14116. 
23. Van Laake LW, Luscher TF, Young ME. The circadian clock in cardiovascular regulation and disease: Lessons from the Nobel Prize in Physiology or Medicine 2017. Eur Heart J. 2018;39(24):2326-9, https://doi.org/10.1093/eurheartj/ehx775.

24. Caruso CC, Waters TR. A review of work schedule issues and musculoskeletal disorders with an emphasis on the healthcare sector. Ind Health. 2008;46(6):523-34, https:// doi.org/10.2486/indhealth.46.523.

25. Fiedler KM, Weir PL, van Wyk PM, Andrews DM. Analyzing what nurses do during work in a hospital setting: A feasibility study using video. Work. 2012;43(4):515-23, https:// doi.org/10.3233/WOR-2012-1419.

26. Buxton OM, Hopcia K, Sembajauthors G, Porter JH, Dennerlein JT, Kenwood C, et al. Relationship of sleep deficiency to perceived pain and functional limitations in hospital patient care workers. J Occup Environ Med. 2012;54(7): 851-8, https://doi.org/10.1097/JOM.0b013e31824e6913.

27. Cao Y, Tang LH, Zhang W, Wang JJ, Yuan ZW, Ling RJ, et al. [Analysis of ergonomic factors for low back pain among airport baggage handlers]. Chin J Ind Med. 2016;4:262-5, https://doi.org/10.13631/j.cnki.zggyyx.2016.04.007. Chinese.

28. Coggon D, Ntani G, Palmer KT, Felli V, Harari R, Barrero LH, et al. Disabling musculoskeletal pain in working populations: Is it the job, the person, or the culture? Pain. 2013;154(6): 856-63, https://doi.org/10.1016/j.pain.2013.02.008.

29. Mei-jing A, Ji-shun W, Rong-ju W, Li-hua C, Shu-lan P, Weijun $\mathrm{G}$, et al. [Epidemiological characteristics of work-related musculoskeletal disorders of back in nurses in a hospital of Tangshan]. J Environ Occup Med. 2016;33(2):152-5, https:// doi.org/10.13213/j.cnki.jeom.2016.15388. Chinese.

This work is available in Open Access model and licensed under a Creative Commons Attribution-NonCommercial 3.0 Poland License - http://creativecommons.org/ licenses/by-nc/3.0/pl/deed.en. 